\title{
Topological design of freely vibrating continuum structures for maximum values of simple and multiple eigenfrequencies and frequency gaps
}

\author{
Jianbin Du • Niels Olhoff
}

Published online: 6 September 2007

(C) Springer-Verlag 2007

Erratum to: Struct Multidisc Optim (2007) 34:91-110

DOI: 10.1007/s00158-007-0101-y

On page 98, in equation (25d), and on page 99, in equations (26f) and (26g)

In the typesetting of equations (25d), (26f) and (26g), it was omitted to insert the symbol " $\Delta$ " between the symbol " $\delta_{s k}$ " and the expression " $\left(\omega^{2}\right)$ ". Thus, these three equations should read

$$
\begin{gathered}
\operatorname{det}\left[\mathbf{f}_{s k}^{\mathbf{T}} \Delta \rho-\delta_{s k} \Delta\left(\omega^{2}\right)\right]=0, \\
s, k=n, \ldots, n+N-1,
\end{gathered}
$$

$$
\begin{gathered}
\operatorname{det}\left[\mathbf{f}_{s k}^{\mathbf{T}} \Delta \rho-\delta_{s k} \Delta\left(\omega^{2}\right)\right]=0, \\
s, k=n, \ldots, n+N-1,
\end{gathered}
$$

$$
\begin{gathered}
\operatorname{det}\left[\mathbf{f}_{s k}^{\mathbf{T}} \Delta \rho-\delta_{s k} \Delta\left(\omega^{2}\right)\right]=0, \\
s, k=n-R, \ldots, n-1,
\end{gathered}
$$

On page 100, in bottom line of caption for Figure 2 “ $\omega_{1 a}^{\phi}=68.7, \omega_{1 b}^{\phi}=104.1$ ” should read " $\omega_{1 a}^{0}=68.7$, $\omega_{1 b}^{0}=104.1 "$

The online version of the original article can be found at http://dx.doi. org/10.1007/s00158-007-0101-y.

J. Du $\cdot$ N. Olhoff $(\bowtie)$

Department of Mechanical Engineering, Aalborg University,

9220 Aalborg East, Denmark

e-mail: no@ime.aau.dk

J. Du

e-mail: jd@ime.aau.dk 